\title{
INTERVENTION FOR OCCUPATIONAL FATIGUE AND SLEEPINESS AMONG HEALTHCARE WORKERS WORKING IN SHIFT: A SYSTEMATIC REVIEW
}

\author{
Mohd Fadhli Mohd Fauzi ${ }^{1,2}$, Hanizah Mohd Yusoff ${ }^{1}$, Mohd Rizal Abd Manaf ${ }^{1}$, Nazarudin Safian', \\ Muhammad Aklil Abd Rahim ${ }^{1,3}$, Mohd Faizal Madrim ${ }^{1,3}$, Azman Atil @ Azmi ${ }^{1,3}$, Ammar Amsyar Abdul \\ Haddi $^{1,2}$ and Nur Adibah Mat Saruan ${ }^{1,2}$
}

'Department of Community Health, Faculty of Medicine, Universiti Kebangsaan Malaysia Medical Centre, Jalan Yaacob Latiff, Bandar Tun Razak, 56000 Cheras, Kuala Lumpur, Malaysia.

${ }^{2}$ Ministry of Health Malaysia, Block E1, E3, E6, E7 \& E10, Complex E, Federal Government Administrative Centre, 62590 Putrajaya, Malaysia Ministry of Health, Malaysia

${ }^{3}$ Department of Community and Family Medicine, Faculty of Medicine and Health Sciences, Universiti Malaysia Sabah, Jalan UMS, 88400 Kota Kinabalu, Sabah, Malaysia

Corresponding author: Hanizah Mohd Yusoff

E-mail: drhanie@ppukm.ukm.edu.my

\section{ABSTRACT}

Healthcare workers typically work in shift to ensure smooth operation of healthcare industries around the clock. However, working in shift put them at risk of developing occupational fatigue and sleepiness during and after work, with multiple adverse effects to themselves and patients under their care. This review aims to identify available evidence-based intervention for fatigue and sleepiness among healthcare workers working in shift. We searched PubMed, Scopus and CENTRAL database from January 2013 to December 2017. Selection criteria included randomised controlled trials (RCTs) that investigated the effect of any interventions on fatigue and/or sleepiness among shift workers. Two authors independently screened titles and abstracts for relevant studies, extracted data, and assessed risk of bias. We included 8 relevant trials with 7 review-relevant participants. Given the methodological diversity of the included studies in terms of interventions and assessment tools, it is not possible to determine the effectiveness of these interventions to reduce occupational fatigue or sleepiness among healthcare workers working in shift. More good quality RCTs with comparable assessment tools is needed.

Keyword: healthcare workers, fatigue, sleepiness, shift work, on-call, intervention

\section{INTRODUCTION}

Healthcare sector is one of the important industries runs for 24 hours, and thus need a shift system to ensure their uninterrupted operation. Shift work is defined by International Labor Organization (ILO) as "a method of organization of working time in which workers succeed one another at the workplace so that the establishment can operate longer than the hours of work of individual workers"1. Health and Safety Executive (HSE) defined shift work as " $a$ work schedules outside standard daytime hours where there is typically a duty handover from one or more employee/s to another employee/s within a 24-hour period"2. On-call duty is commonly included as shift work. In current practice among medical doctor in Malaysia, oncall duty means that they commonly have to work at least for 24 hours continuously from $0800 \mathrm{H}$ to $0800 \mathrm{H}$ subsequent day, and usually have to resume another 4 hours to 9 hours as normal day work.

In healthcare sectors, varieties of occupations exist, including medical doctors, nurses, paramedics, and health attendants who usually undergone a shift system. In certain countries including Malaysia, most medical doctors are still involved in on-call duties, in which most of them will come to work at $0800 \mathrm{H}$ and finished their jobs at $1700 \mathrm{H}$ the next day during on-call. Others may involve in different type of shift work such as rotating shift and fixed odd hour shift ${ }^{3}$. Shift work may be unavoidable especially in limited human resource setting ${ }^{4}$.

Working in shift may be beneficial to the employers or clients as they can access the service for 24 hours, but it is not without risk to the employees. Studies have shown that, as compared to non-shift workers, shift workers are more likely to have adverse safety and health effects ${ }^{5-8}$ including fatigue and sleepiness.

Occupational fatigue and sleepiness are wellknown hazards in many industries, including healthcare sector. During night shift or on-call duty, they are prone to develop occupational fatigue and sleepiness, which put them and patient under their care to multiple adverse effects such as prescription error and needlestick injury 9 . After night shift or post-call duty, they are at risk of commuting accident ${ }^{10}$ while travelling home. In Malaysia, from 2014 till 2016, there were 554 reported cases of commuting accidents 
involving healthcare workers from public hospitals under Ministry of Health Malaysia $(\mathrm{MOH}) ; 69$ of them were going home after work outside of typical office hours, with few fatal cases reported ${ }^{11}$. Long working hours, especially commuting after night shift is one of the recognized factors for fatigue-related motor vehicle accident $(M V A)^{10}$.

Thus, it is important to introduce and implement effective interventions for occupational fatigue and sleepiness among healthcare workers working in shift in order to minimize the adverse risk to the workers as well as patients under their care. This study aims to identify available recent evidence-based interventions and their outcomes for fatigue and sleepiness among healthcare workers working in shift.

\section{METHODOLOGY}

\section{Search Strategy}

We searched the following databases: the Cochrane Central Register of Controlled Trials (CENTRAL), PubMed and Scopus. List of all relevant studies from January 2013 until December 2017 was screened.

We used a search strategy specifically designed for PubMed and subsequently adapted for other relevant databases. We used the following keywords "fatigue", "asthenia", "lassitude", "tiredness", "lethargy", "sleepiness", "drowsiness" and "shift work", "oncall", "oncall". We used other term which denoted shift work which is "oncall" or "on-call". As fatigue is frequently interchangeably referred to sleepiness, we also include the term sleepiness and drowsiness into search strategy. As for intervention and population, we did not specify any type of intervention or population in search strategy in order to increase number of articles being captured by the database search engines.

\section{Inclusion and exclusion criteria}

We included full-text randomised controlled trials in English language. We included studies conducted with healthcare workers engaged in shift work schedules that include night-shift work and on-call duty. However, due to scanty search result, we expanded our inclusion criteria to include other similar workers irrespective of industry as well as laboratory-simulated shift workers. We restrict our review to those with no known sleep problems such as insomnia, obstructive sleep apnoea and shift work disorders. We included any types of interventions for occupational fatigue and sleepiness.

\section{Primary Outcomes}

Primary outcomes are fatigue and sleepiness. Fatigue itself has no gold standard of measurement. It could be measured either objectively or subjectively. Objective measurements include electro-oculography (EOG) and blink rates. Perceived fatigue level could be measured with few types of questionnaire such as visual analogue score. The effect measurement would be mean fatigue level. The gold standard for sleepiness measurement is polysomnography. It can be measured in multiple perspectives, either objectively such as sleep depth, sleep stages and sleep duration, or subjectively in term of perceived sleepiness level. The effect measurement would be mean sleepiness level and/or mean score of sleep quality and/or mean Bispectral index (BIS) level and/or mean sleep duration. Other correlates of fatigue and sleepiness would be considered too, such as mean reaction time.

\section{Data collection and analysis}

Two review authors independently screened titles and abstracts of all the studies identified as a result of the search. The pairs included some combination of authors. They coded these as retrieve (eligible or potentially eligible / unclear) or do not retrieve. Any disagreement was resolved through discussion among those pairs or by third author. We retrieved all eligible or potentially eligible / unclear full-text study articles. We recorded the selection process in sufficient detail to complete a PRISMA flow diagram. Next, same pairs of authors independently extracted trial data. Data extracted included authors, designs, participants, locations, interventions, outcome domains, risk of bias and outcomes. Disagreement was resolved by discussion with third author.

They subsequently assessed the risk of bias of the included studies across the following eight domains: (1) sequence generation; (2) allocation concealment; (3) blinding of participants and personnel; (4) blinding of outcome assessors; (5) incomplete outcome data; (6) selective outcome reporting; (7) outcome reliably or objectively measured; (8) other sources of bias. Risk of bias rating was categorized to low (all domains have a low risk of bias), high (at least one domain has a high risk of bias) or unclear (at least one domain has unclear risk of bias provided no domain has a high risk of bias).

Homogeneity was assessed based on similarities of interventions, populations, shift schedules, exact outcome definitions, outcome timing and followup. However, it was found that the studies were too heterogenous to pool. 


\section{RESULTS}

Figure 1 shows the PRISMA study flow diagram of included and excluded studies. The electronic databases search resulted in a total of 224 references. After removal of 56 duplicates, a total of 168 references remained. Based on titles and abstracts screening, eight potentially relevant references were identified for which we retrieved full text articles. Of these, a total of seven randomized-controlled trials (RCTs) met our inclusion criteria for this review (five studies involved healthcare workers and two involved non-healthcare workers). Table 1 showed the summary of the studies characteristic that was involved in this systematic review.

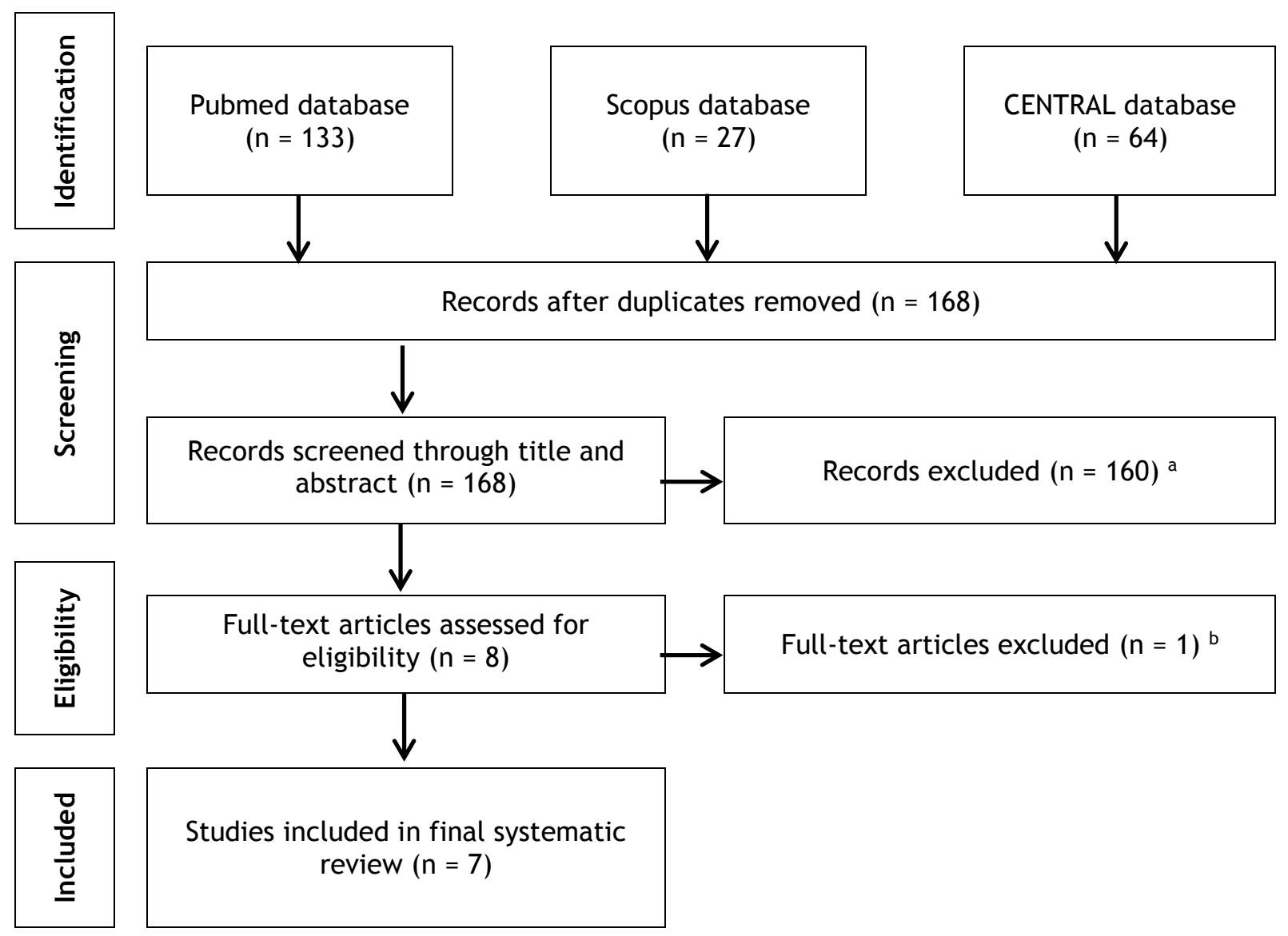

a excluded because the titles and/or abstracts were not relevant to our study

${ }^{b}$ excluded because the outcomes were not fatigue and/or sleepiness

Figure 1: Flow chart of article search strategy according to PRISMA statements.

\section{DISCUSSION}

The results will be discussed as per outcome domains, interventions used and based on individual studies. A summary of quantitative measure was not possible due to the nature of the studies assessed. The studies were too heterogenous in terms of the outcome domains measured, assessment tools used, and types of intervention. Further, no studies were deemed of low risk for bias in methodology; two studies had an overall uncertain risk ${ }^{13,16}$ while the other five showed high risk for bias ${ }^{12,14-15,17-18}$. Due to the reasons mentioned, conducting a quantitative summary measure was not possible, let alone valid.

The effectiveness of interventions in studies with uncertain risk of bias is first discussed. Hilditch et al. $(2016)^{16}$ conducted a quasi-randomised controlled trial whereby participants were given nap time during night shift and sleep inertia/performance were evaluated post-nap. It was found that 10-minute nap, but not 30-minute nap, was able to mitigate short-term performance impairment during a simulated night shift. The performance of participants in the 30-minute nap intervention group was shown to be worse postnap, as explained by the effects of sleep inertia. The same effects was markedly reduced in the 10minute nap group. There was significant improvement in performance for those who had 10-minute nap compared to control, while no significant difference was observed in the 30 minute nap intervention group as compared to control. The sleep inertia battery tests which had significant result favouring 10-minute nap were psychomotor vigilance test and digit-symbol substitution task. 
Table 1: Characteristic of studies involved

\begin{tabular}{|c|c|c|c|c|c|c|c|}
\hline Authors & Design & Participants & Location & Intervention & $\begin{array}{l}\text { Outcome } \\
\text { Domain }\end{array}$ & $\begin{array}{l}\text { Risk } \\
\text { of } \\
\text { Bias }\end{array}$ & Outcome \\
\hline $\begin{array}{l}\text { Rahman } \\
\text { et al. } \\
(2013)^{12}\end{array}$ & RCT (field) & 9 nurses & Canada & $\begin{array}{l}\text { Filtered } \\
\text { light / } \\
\text { glasses }\end{array}$ & $\begin{array}{l}\text { Alertness } \\
\text { (PVT), } \\
\text { quality of } \\
\text { sleep } \\
\text { (sleep } \\
\text { study) and } \\
\text { affect } \\
\text { measures }\end{array}$ & High & $\begin{array}{l}\text { Significant } \\
\text { difference in } \\
\text { increasing } \\
\text { alertness in } \\
\text { favour of } \\
\text { intervention }\end{array}$ \\
\hline $\begin{array}{l}\text { Punja et } \\
\text { al. } \\
(2014)^{13}\end{array}$ & RCT (field) & $\begin{array}{l}36 \text { nursing } \\
\text { students }\end{array}$ & Canada & $\begin{array}{l}R \text {. rosea } \\
\text { plant } \\
\text { extract } \\
\text { health } \\
\text { product }\end{array}$ & $\begin{array}{l}\text { Fatigue } \\
\text { (RAND-36) }\end{array}$ & $\begin{array}{l}\text { Un- } \\
\text { clear }\end{array}$ & $\begin{array}{l}\text { Significant } \\
\text { difference in } \\
\text { favour of } \\
\text { placebo }\end{array}$ \\
\hline $\begin{array}{l}\text { Oriyama } \\
\text { et al. } \\
(2014)^{14}\end{array}$ & RCT (field) & $\begin{array}{l}15 \text { female } \\
\text { nurses }\end{array}$ & Japan & $\begin{array}{l}\text { Two } 15- \\
\text { minutes nap } \\
\text { breaks }\end{array}$ & $\begin{array}{l}\text { Fatigue } \\
\text { and } \\
\text { sleepiness } \\
\text { (VAS) }\end{array}$ & High & $\begin{array}{l}\text { No significant } \\
\text { difference }\end{array}$ \\
\hline $\begin{array}{l}\text { Patterson } \\
\text { et al. } \\
(2015)^{15}\end{array}$ & $\begin{array}{l}\text { Two- } \\
\text { armed, } \\
\text { Parallel } \\
\text { RCT (field) }\end{array}$ & $\begin{array}{l}85 \text { US-based } \\
\text { emergency } \\
\text { medicine } \\
\text { clinicians }\end{array}$ & $\begin{array}{l}\text { United } \\
\text { States } \\
\text { (US) }\end{array}$ & $\begin{array}{l}\text { Text } \\
\text { messages to } \\
\text { inform on } \\
\text { strategies to } \\
\text { reduce } \\
\text { fatigue and } \\
\text { sleepiness }\end{array}$ & $\begin{array}{l}\text { Sleepiness } \\
\text { (PSQI, } \\
\text { ESS) and } \\
\text { fatigue } \\
\text { (CFQ, } \\
\text { OFER) }\end{array}$ & High & $\begin{array}{l}\text { Significant } \\
\text { difference in } \\
\text { mean sleep } \\
\text { quality scores } \\
\text { favouring the } \\
\text { intervention }\end{array}$ \\
\hline $\begin{array}{l}\text { Hilditch } \\
\text { et al. } \\
(2016)^{16}\end{array}$ & $\begin{array}{l}\text { Quasi-RCT } \\
\text { (lab.) }\end{array}$ & $\begin{array}{l}31 \text { healthy } \\
\text { adults }\end{array}$ & Australia & $\begin{array}{l}10-\text { minute } \\
\text { and } 30- \\
\text { minute naps }\end{array}$ & $\begin{array}{l}\text { Fatigue } \\
\text { (PVT) and } \\
\text { sleepiness } \\
\text { (self- } \\
\text { report) }\end{array}$ & $\begin{array}{l}\text { Un- } \\
\text { clear }\end{array}$ & $\begin{array}{l}\text { Significant } \\
\text { improvement } \\
\text { in outcome } \\
\text { domain for } \\
\text { 10-minute } \\
\text { nap }\end{array}$ \\
\hline $\begin{array}{l}\text { Leedo et } \\
\text { al. } \\
(2017)^{17}\end{array}$ & $\begin{array}{l}\text { 8-week } \\
\text { Cross-over } \\
\text { Trial } \\
\text { (field) }\end{array}$ & $\begin{array}{l}59 \\
\text { physicians, } \\
\text { nurses and } \\
\text { nursing } \\
\text { assistants }\end{array}$ & Denmark & $\begin{array}{l}\text { Healthy } \\
\text { meal }\end{array}$ & $\begin{array}{l}\text { Fatigue } \\
\text { (PVT) and } \\
\text { mood- } \\
\text { related } \\
\text { measures }\end{array}$ & High & $\begin{array}{l}\text { Significant for } \\
\text { mood-related } \\
\text { measures } \\
\text { among shift } \\
\text { workers in } \\
\text { favour of } \\
\text { intervention }\end{array}$ \\
\hline $\begin{array}{l}\text { Sletten } \\
\text { et al. } \\
(2017)^{18}\end{array}$ & $\begin{array}{l}\text { RCT } \\
\text { Parallel } \\
\text { Design } \\
\text { (lab.) }\end{array}$ & $\begin{array}{l}71 \text { night } \\
\text { shift workers }\end{array}$ & Australia & $\begin{array}{l}17 k \text { blue- } \\
\text { enriched } \\
\text { white light }\end{array}$ & $\begin{array}{l}\text { Attention } \\
\text { (PVT) }\end{array}$ & High & $\begin{array}{l}\text { No significant } \\
\text { difference }\end{array}$ \\
\hline
\end{tabular}


In a study conducted by Punja et al. $(2014)^{13}$, where the risk of bias was deemed unclear, participants were randomised to take $\mathrm{R}$. rosea capsule, a type of plant used as a natural herbal health product, to reduce fatigue among nursing students. It was noted that the mean change in scores on Vitality-subscale was significantly different between the study groups in favour of placebo (-17.3 (95\% Cl: -30.6, -3.9), $\mathrm{p}=0.011)$. The mean change in scores on the Visual Analog Score of Fatigue (VAS-F) was also significantly difference between study groups in favour of placebo $(1.9(95 \% \mathrm{Cl} 0.4,3.5), \mathrm{p}=0.015)$. Total number of adverse events did not differ between $\mathrm{R}$. rosea and placebo group. The study showed that $R$. rosea had in fact worsened fatigue, although further evidence is needed to come to a definite conclusion.

The other studies that will be discussed had high risk of bias in their methodology. However, the results may still be useful although caution is advised if any of the findings are to be adopted into real working environment. Leedo et al. $(2017){ }^{17}$ had conducted an 8 -week cross-over trial to assess the effects of healthy meal to improve reaction time and mood-related measures in healthcare personnel working in shift duty. The authors found that for those receiving the intervention (healthy meal), they had $31.1 \%$ lower Fatigue-Inertia Score $(P=0.003)$, a $15.3 \%$ higher Vigour-Activity Score $(P=0.041)$ and a $42.7 \%$ lower Total Mood Disturbance Score $(P=0.017)$ compared with the control period. However, the subjective assessment tool to measure the outcome, especially the mood-related measures, may be subjected to bias, as the outcome assessor (the participants themselves) were not blinded to the intervention.

Oriyama et al. (2014) ${ }^{14}$ conducted a randomized controlled trial among nurses to assess the effect of two 15-minutes naps on the perception of sleepiness and fatigue during night shift. A major bias that was found in this study was the small sample size, and also the randomization of intervention allocation, which was not described, and may give rise to significant selection bias. The results in the study, however, showed no significant association between two 15-minute naps and perception of sleepiness and fatigue during night shift.

A two-armed parallel, randomized controlled trial performed by Patterson et al. (2015) $)^{15}$ also had inconclusive results. Text messages were used to promote alertness and a tool for outcome measurement. Text-message queries measured self-rated sleepiness, fatigue, and difficulty with concentration, while additional text-messages were sent to intervention participants to promote alertness. Although there were significant difference in mean sleep quality scores favouring the intervention, this study was subjected to considerable bias due to the self-report outcome measure assessment. In fact, the authors pointed out that the participants may even have altered their responses due to their knowledge of being followed as part of a research study.

The final two studies in this review had a similar approach in assessing the type of intervention to improve performance during shift work; both studies had evaluated the effect of different light spectrums on work performance outcome domains. Rahman et al. (2013) $)^{12}$ had conducted a randomized controlled trial whereby participants were randomized to receive filtered light (intervention) or standard indoor light (baseline) on night shifts. Daytime sleep was significantly impaired under both baseline and intervention conditions. Salivary melatonin levels were significantly higher on the first $(p<0.05)$ and middle $(p<0.01)$ night shifts under intervention compared with baseline. Subjective sleepiness increased throughout the night under both conditions $(p<0.01)$. However, reaction time and throughout on vigilance tests were similar to daytime performance under intervention but impaired under baseline on the first night shift. These results suggest that both daytime and nighttime sleep are adversely affected in rotating-shift workers and that filtering short wavelengths may be an approach to reduce sleep disruption and improve performance in rotating-shift workers.

However, Sletten et al. (2017) ${ }^{18}$ did not come to a concrete conclusion on the application of light spectrum as an intervention to improve shift worker's performance. Subjective and objective sleepiness increased during the night shift in both blue-enriched white light (intervention) and standard white light (control) $(p<0.05)$, but no significant effects of light condition were observed. There was also substantial attrition bias in the study, with which less than $90 \%$ of the initial participants' data were included into the final analysis.

In general, the studies that are included in this review are lacking in methodological robustness. Most evidence shown here were not low risk to bias, especially in detection and performance bias. Even the recruitment of samples in majority of the studies has risk of selection bias so the representativeness of the population in study might not be achieved. Recommendations to be incorporated into national healthcare policy for shift workers may not be valid if only these seven studies are used as references. The inability of systematic review to generate practical policy recommendations to policy-makers is not uncommon ${ }^{19}$. Thus, further trials with low risk of bias in this research area are needed to gain new evidence and to support current available evidences.

Despite inconclusive results, this study may assist in answering arguments from workers. For example, workers may argue that they require 
longer sleep duration, but Hilditch et al. (2016) ${ }^{16}$ showed that shorter 10-minutes nap as compared to 30-minutes nap, was able to mitigate shortterm performance impairment. Others may claim that multiple sleep breaks during night shift are required, but Oriyama et al. (2014) ${ }^{14}$ showed that two 15-minutes nap breaks had no significant association with perceived sleepiness and fatigue. However, since a policy should cover population instead of individual needs, this review provides valuable information to policy makers that some interventions may not be as effective as it thought it would be ${ }^{20}$.

\section{CONCLUSION}

This systematic review reveals that recent interventions studies for occupational fatigue and sleepiness among shift workers are too heterogenous to be compared among them. The number of RCTs that investigate this kind of intervention is also limited, particularly among healthcare workers. As 24-hours service for healthcare industry is a must and shift work among healthcare worker is not avoidable, there is an urgent need to consider more RCTs that are comparable with high evidence of quality.

\section{ACKNOWLEDGMENT}

The authors wish to thank Department of Community Health, Faculty of Medicine, Universiti Kebangsaan Malaysia Medical Centre in providing assistance in this study.

\section{COMPETING INTEREST}

There is no conflict of interest.

\section{FUNDING SOURCE}

This review was funded by Geran Peneraju Cabaran Perdana (GIP-2018-005) under Universiti Kebangsaan Malaysia.

\section{REFERENCES}

1. International Labour Organization. Night Work Convention. C171, Geneva, ILO. 1990.

2. Health and Safety Executive. Managing shiftwork: Health and safety guidance. 2006.

3. Health and Safety Executive. Changes in shift work patterns over the last ten years (1999 to 2009). 2011.

4. Ning-Zi Sun \& Thomas Maniatis. Scheduling in the context of resident duty hour reform. BMC Medical Education 2014; 14(Suppl 1):S18

5. Kivimäki M, Batty GD, Hublin C. Shift work as a risk factor for future type 2 diabetes: evidence, mechanisms, implications, and future research directions. PLOS Medicine 2011; 8(12):e1001138.

6. Vyas Manav V, Garg Amit X, lansavichus Arthur V, Costella John, Donner Allan, Laugsand Lars $E$ et al. Shift work and vascular events: systematic review and meta-analysis. BMJ 2012; 345 :e4800

7. Torquati L, Mielke GI, Brown WJ, KolbeAlexander T. Shift work and the risk of cardiovascular disease. A systematic review and meta-analysis including dose-response relationship. Scand J Work Environ Health 2017; pii:3700.

8. Yuan X, Zhu C, Wang M, Mo F, Du W, Ma X. Night Shift Work Increases the Risks of Multiple Primary Cancers in Women: A Systematic Review and Meta-analysis of 61 Articles. Cancer Epidemiol Biomarkers Prev. 2018; 27(1):25-40.

9. Kavitha Nagandla, Krishna Kumar, Amit Bhardwaj, Devalagan a/l Muthalagan, Chan Yhmin, Lee Wei Lun, Weng Wei Shi, Nurul Izzati B. Abd Razak. Prevalence of needle stick injuries and their underreporting among healthcare workers in the department of obstetrics and gynaecology. iMedPub Journals 2015; 8(181)

10. Lee ML, Howard ME, Horrey WJ, Liang $Y$, Anderson C, Shreeve MS, O'Brien CS \& Czeisler CA. High risk of near-crash driving events following night-shift work. Proceedings of the National Academy of Sciences of the United States of America 2016; 113(1):176-181.

11. KPK. Kenyataan Akhbar KPK 31.5.2017 - Isu Kemalangan Jalan Raya di Kalangan Anggota Kesihatan. 2017. https: / / kpkesihatan.com/2017/05/31/kenya taan-akhbar-kpk-31-5-2017-isu-kemalanganjalan-raya-di-kalangan-anggota-kesihatan/ [25 September 2017]

12. Rahman SA, Shapiro CM, Wang F, et al. Effects of Filtering Visual Short Wavelengths During Nocturnal Shiftwork on Sleep and Performance. Chronobiology International 2013; 30(8):951-962.

13. Punja S, Shamseer L, Olson K, Vohra S. Rhodiola Rosea for Mental and Physical Fatigue in Nursing Students: A Randomized Controlled Trial. Walker N, ed. PLoS ONE. 2014; 9(9):e108416.

14. Oriyama S, Miyakoshi $Y$, Kobayashi T. Effects of Two 15-min Naps on the Subjective Sleepiness, Fatigue and Heart Rate Variability of Night Shift Nurses. Industrial Health 2014; 52(1):25-35. 
15. Patterson PD, Buysse DJ, Weaver MD, et al. Real-Time Fatigue Reduction in Emergency Care Clinicians: The SleepTrackTXT Randomized Trial. American journal of industrial medicine 2015; 58(10):1098-1113.

16. Hilditch CJ, Centofanti SA, Dorrian J, Banks S. A 30-Minute, but Not a 10-Minute Nighttime Nap is Associated with Sleep Inertia. Sleep 2016; 39(3):675-685.

17. Leedo E. Beck AM, Astrup A \& Lassen AD. The effectiveness of healthy meals at work on reaction time, mood and dietary intake: $\mathrm{A}$ randomised cross-over study in daytime and shift workers at an university hospital. British Journal of Nutrition 2017; 118:121-129.

18. Sletten TL, Ftouni S, Nicholas CL, Magee $M$, Grunstein RR, Ferguson S, Kennaway DJ, O'Brien D, Lockley SW \& Rajaratnam SMW. Randomised controlled trial of the efficacy of a blue-enriched light intervention to improve alertness and performance in night shift workers. Occup Environ Med 2017; 74(11):792-801.

19. Richard Mallett, Jessica Hagen-Zanker, Rachel Slater \& Maren Duvendack. The benefits and challenges of using systematic reviews in international development research. Journal of Development Effectiveness 2012; 4(3):445455.

20. Urra Medina E \& Barría Pailaquilén RM. 2010. Systematic review and its relationship with evidence-based practice in health. Rev Lat Am Enfermagem. 18(4):824-31. 